
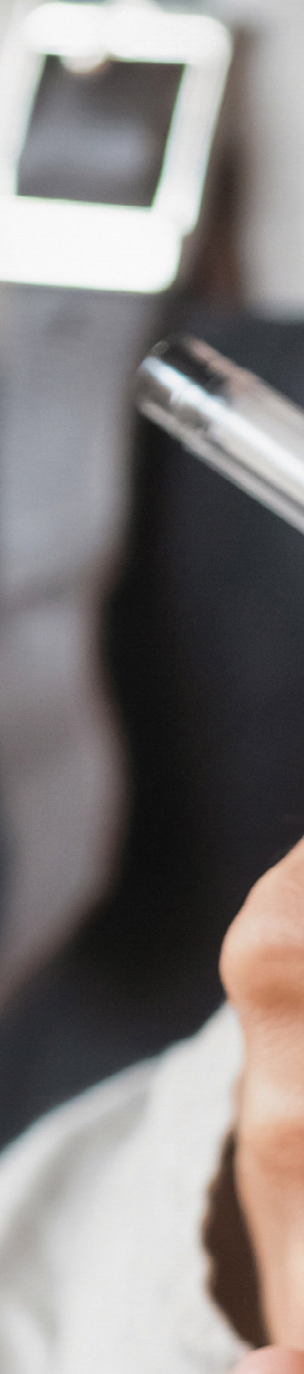


\section{VENDEDORES DE PORTAS ABERTAS}

| POR CAIO FABER DE CASTRO, LUCAS SCIENCIA DO PRADO E VERÔNICA ANGÉLICA FREITAS DE PAULA

\section{Pesquisa mostra que o atendimento nas lojas é fator essencial para o consumidor ficar ou não satisfeito com sua experiência de compra. Assim, varejistas precisam concentrar esforços em contratar, treinar, gerenciar e engajar sua equipe de vendas.}

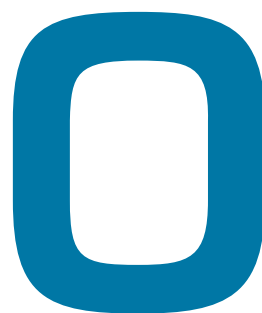

que faz os clientes recomendarem ou, ao contrário, contraindicarem uma loja? Movidos por essa questão, realizamos uma pesquisa com clientes de um grande varejista nacional. $\mathrm{O}$ fator de maior importância, tanto no caso dos promotores como no dos detratores, foi o atendimento dos colaboradores nas lojas da empresa.

Mesmo com toda a digitalização do varejo, a força de vendas e de atendimento nas lojas permanece como um ponto de contato decisivo para o consumidor, mas de forma diferente em relação a tempos atrás. Os clientes promotores do varejista pesquisado não demonstraram valorizar aspectos como o entendimento de suas necessidades e a apresentação de opções de produtos, provavelmente porque já chegam à loja sabendo o que vão comprar. As qualidades elogiadas por eles são cordialidade e objetividade. Ou seja, esperam ser bem tratados, entretanto sem grandes rodeios, com especialistas ajudando-os no processo de conclusão da decisão. O que os clientes detratores indicam aponta na mesma direção, pois se sentiram mal atendidos e consideraram que os vendedores procuraram empurrar produtos que não eram de seu interesse.
A fim de compreender o que faz uma equipe de atendimento ser bem considerada nas lojas mais recomendadas pelos clientes, entrevistamos seus gerentes. Destacaram-se quatro características principais: qualidade da gestão, perfil dos atendentes, treinamento da equipe e engajamento, com ampliação dos pontos de contato com o cliente.

\section{QUALIDADE DA GESTÃO}

Faz enorme diferença ter uma liderança à frente da loja, atenta aos problemas que surgem ao longo do dia e capaz de ajudar os colaboradores da linha de frente a fazerem o atendimento com foco e tranquilidade. Os gestores das lojas mais recomendadas são muito presentes e prestam atenção aos mínimos detalhes.

Tanto o gerente como o supervisor fazem a gestão pelo exemplo e, caso seja necessário, atendem eles mesmos os clientes, o que serve para mostrar boas práticas à equipe. Foi assim, por exemplo, que um gerente percebeu que os consumidores ficavam incomodados quando as prateleiras eram abastecidas com a loja aberta. Então, ele resolveu dividir seu time em dois: um para repor as mercadorias antes de as portas abrirem e outro para atender os clientes. A equipe de reposição também ganhou know-how em visual 


\section{AS DIFERENCCAS NAS ATITUDES DAS LOJAS MAIS E MENOS RECOMENDADAS*}

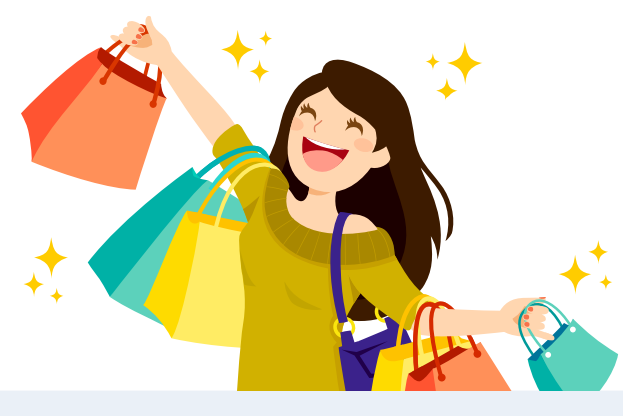

Lojas com consumidores promotores

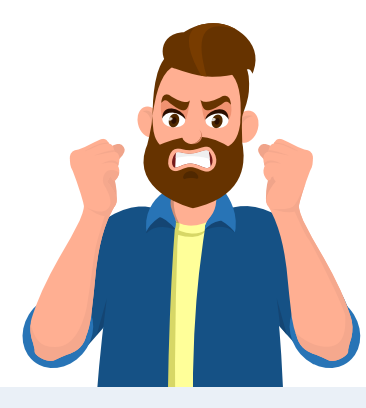

Lojas com consumidores insatisfeitos
- Escolha do perfil adequado de atendente e vendedor;

- Cuidado com a contratação de profissionais;

- Treinamento contínuo e adicional da equipe;

- Envolvimento dos colaboradores na disseminação de boas práticas;

- Estímulo a ações inovadoras;

- Atenção gerencial das lideranças da loja.
- Existência de vendedores com perfil desconexo à função;

- Rotatividade de vendedores;

- Falta de conhecimento de produtos e de como atender;

- Falta de atenção gerencial ao atendimento. merchandising, e a loja, além de mais bonita e bem arrumada, passou a expor melhor produtos considerados como estratégicos no momento.

Os gestores também costumam perguntar aos clientes como foi a compra, de maneira a mostrar que se importam com sua opinião e com seu feedback. Quando uma consumidora relatou que só não ficava mais tempo na loja porque seu marido não tinha onde esperá-la durante as compras, o gerente colocou um sofá próximo à escada rolante.

Além disso, os gestores posicionam os colaboradores nos papéis em que possam melhor contribuir para a operação. Com relação às metas, a equipe sabe quais são os objetivos do grupo, mas não de cada departamento ou produto, para que possam priorizar sua atenção ao que o cliente precisa.

\section{PERFIL DOS ATENDENTES}

Os gestores das melhores lojas da rede varejista tomam muito cuidado ao contratar atendentes. Utilizam ferramentas como o teste de predictive index (PI) para fazer levantamento do perfil dos candidatos e avaliar suas motivações

\section{Lojas em que clientes estão mais satisfeitos contam com gestores atentos aos mínimos detalhes; atendentes atualizados, cordiais e flexiveis; equipe bem treinada; e colaboradores engajados e prontos a perceber oportunidades para inovar.}

e seus comportamentos. Também se preocupam em contratar profissionais que tenham vivência como consumidores do departamento, para que assim possam compreender as necessidades dos clientes. A experiência do quadro de 
atendentes também se destaca nas lojas mais recomendadas. Em uma delas, a equipe está há mais de 10 anos trabalhando no atendimento. Portanto, é possível estabelecer vínculos com a clientela, entendendo quem gosta de atenção e quem prefere não ser incomodado.

Os atendentes das lojas mais bem avaliadas apresentaram características como boa comunicação e articulação das ideias, criação de empatia com os clientes, adaptabilidade e flexibilidade, conhecimento e atualização constante sobre a categoria de produtos e disseminação de boas práticas para os demais colegas.

Os vendedores passam a ser vistos como referências para recomendar produtos aos clientes da loja, pois trabalham com o foco nas necessidades e possuem bom conhecimento da categoria que representam.

\section{TREINAMENTO}

Além dos treinamentos (obrigatórios) oferecidos pela matriz, a loja promove treinamentos de aprofundamento e reciclagem, realizados pelos próprios colaboradores. Assim, quando surge alguma novidade ou tendência, um colaborador da loja é responsável por organizar um treinamento curto para ser aplicado nas reuniões de abertura de loja ou nas reuniões semanais para os colaboradores diretos do departamento e dos demais. Além da reciclagem e da atualização promovidas, essas práticas proporcionam o engajamento e o desenvolvimento de habilidades de apresentação.

\section{ENGAJAMENTO COM AMPLIAC̣ÃO DOS PONTOS DE CONTATO}

Ações inovadoras são estimuladas nas lojas em que consumidores estão mais satisfeitos. Quando uma cliente perguntou a um colaborador se poderia ser avisada por WhatsApp da chegada de um produto esgotado, o vendedor resolveu criar um grupo no aplicativo para clientes assíduos que gostariam de saber de novidades, promoções e reposição de estoque. Esse é um tipo de ação que aproxima vendedores e consumidores mesmo quando estes não estão nas lojas. No período da pandemia em que as lojas ficaram fechadas, os grupos de WhatsApp ajudaram a manter o relacionamento com os clientes.

Outro exemplo de ação inovadora foi quando uma cliente fiel disse ao vendedor que gostaria de ganhar presentes de casamento da loja. Como o varejista não contava com um processo para lista de presentes, a própria equipe da loja criou a dinâmica juntamente com a cliente. Deu tão certo que a loja passou a disponibilizar o serviço.

\section{MÉTRICAS DE DESEMPENHO}

A pesquisa mostra que a satisfação do consumidor é uma métrica importante para a avaliação do desempenho e sucesso da força de venda dos varejistas. Essa métrica tecnicamente é conhecida como net promoter score (NPS). Ao fim da interação com a empresa, o consumidor faz uma avaliação em uma escala de 0 a 10 . Notas de 0 a 6 representam os detratores; 7 e 8 , os neutros; e 9 e 10, os promotores da marca. $O$ cálculo da métrica é feito com base no percentual de promotores menos o de detratores.

A literatura acadêmica apresenta vantagens e desvantagens da métrica. Por isso, é importante não só calculá-la, como também avaliar os motivos que levam os consumidores a recomendar ou não a marca. Assim, leva-se em consideração não apenas o fim da experiência do consumidor, mas todas as atividades na jornada de consumo. Além disso, o NPS pode ser combinado com outras tradicionais métricas de desempenho, como taxa de conversão, vendas por metro quadrado, vendas por funcionários, vendas por vendedor ou mesmo ticket médio.

No caso do varejista estudado, a nota de NPS de cada loja já influencia na participação nos lucros dos gerentes de lojas. Logo, há o estímulo para que aprimorem a gestão da equipe e estejam mais atentos à satisfação dos clientes. A pesquisa também estimulou a empresa a iniciar o pagamento de comissão em duas lojas abertas há menos de seis meses. A empresa já tem percebido que essas lojas piloto vêm apresentando NPS superior àquele das lojas que não trabalham com comissionamento.

Com os esforços do varejo para aprimorar a experiência online do cliente, que foram intensificados após o início da pandemia, o próximo desafio será não gerar uma fricção na tomada de decisão do consumidor que optar por concluir seu processo de compra na loja física. Para isso, serão fundamentais repensar o papel dos vendedores em loja e avaliar o impacto de seu atendimento na satisfação dos consumidores.

\footnotetext{
PARA SABER MAIS:

- Caio Faber de Castro. Análise do papel dos vendedores na satisfação de cliente por meio do NPS (Net Promoter Score). Evidências do varejo de moda omnichannel brasileiro, 2020.

Frederick F. Reichheld. The one number you need to grow. Harvard Business Review, 2003. Christina Stahlkopf. Where Net Promoter Score goes wrong. Harvard Business Review, 2019.

Thales S. Teixeira e Renato Mendes. How to improve your company's Net Promoter Score. Harvard Business Review, 2019.

CAIO FABER DE CASTRO > Gerente de produto nas Lojas Riachuelo e mestre pelo Mestrado Profissional em Gestão para Competitividade (MPGC) da FGV EAESP > caiofaber.adm@gmail.com

LUCAS SCIENCIA DO PRADO > Professor da FGV EAESP > lucas.sciencia@fgv.br VERÔNICA ANGÉLICA FREITAS DE PAULA > Professora da Faculdade de Gestão de Negócios da Universidade Federal de Uberlândia > veronica@ufu.br
} 